\title{
PODER DE VIDA OU MORTE NA JUDICIALIZAÇÃO DA SAÚDE - (MACROFILOSOFIA E A FORMAÇÃO HUMANÍSTICA INTERDISCIPLINAR DO MAGISTRADO) \\ Luiz Fernando Belinetti ${ }^{1}$ Artur César de Souza ${ }^{2}$
}

Resumo: A judicialização da saúde tem exigido cada vez mais do magistrado uma especial atenção quanto à justiça e a legitimidade de sua decisão. Nela, a observância e a eficácia dos direitos humanos (direito à vida e à saúde) tornam-se mais evidentes e exigem maior sensibilidade do magistrado para sua análise e interpretação jurídica. Diante dessa preocupante problematização, tem-se constatado que a simples formação acadêmica dogmática do juiz não tem sido suficiente para garantir uma decisão justa e équo em questões sobre o direito à saúde, tendo em vista que tal matéria envolve outras complexidades além da interpretação da norma jurídica. Este trabalho tem por objetivo apontar um fio condutor legitimador que garanta a proximidade da decisão judicial a um resultado mais justo diante da realidade social

Palavras-chaves: Decisão judicial. Saúde. Interdisciplinar. Intercultural. Macrofilosofia.

\section{POWER OF LIFE OR DEATH IN HEALTH JUDICIALIZATION - (MACROFILOSOPHY AND THE HUMANISTIC FORMATION INTERDISCIPLINARY OF THE MAGISTRATE)}

\begin{abstract}
The judicialization of health has increasingly required the magistrate to pay special attention to the justice and legitimacy of his decision. In it, the problematization of human rights (right to life and health) becomes more evident and demands greater sensitivity of the magistrate for its analysis and legal interpretation. Faced with this worrying problematization, it has been observed that the mere dogmatic academic formation of the magistrate has not been enough to guarantee a fair and efficient decision on questions about the right to health, considering that this matter involves other complexities besides the interpretation of the norm legal basis. Hence why this work aims to find a legitimating criterion that can approximate the decision of the judge to a fairer result before the social reality
\end{abstract}

Keywords: Judicial decision. Health. Interdisciplinary. Intercultural. Macrophilosophy.

\section{Introdução}

\footnotetext{
$1 \quad *$ Mestre em Direito pela UEL e Doutor em Direito pela PUC-SP. Procurador de Justiça Aposentado. Advogado. Professor dos Cursos de graduação e pós-graduação em Direito da UEL. e-mail: luizbel@uol.com.br . Endereço: Departamento de Direito Privado/CESA/UEL. Rodovia Celso Garcia Cid, PR-445, Km 380 Campus Universitário, Londrina - PR, 86057-970. - luizbel@uol.com.br

$2 *$ Doutor pela Universidade Federal do Paraná - UFPR e Mestrando pela Universidade Estadual de Londrina-arturcesarsouza@gmail.com
} 
Na Conferência Internacional sobre os Cuidados Primários da Saúde, ocorrida na cidade de Alma-Ata, no atual Cazaquistão, aprovou-se a declaração de Alma-Ata, de 1978, na qual se recomendou uma especial atenção às políticas públicas de saúde, inserindo-a como objetivo principal a ser perseguido internacionalmente, mediante comunhão de esforços de todos os governos e de todos os envolvidos na promoção da Saúde.

Durante a conferência, reforçou-se a nível internacional que a saúde - estado completo, bem-estar físico, mental e social, e não simplesmente a ausência de doença ou enfermidade - é um direito humano fundamental, e que a consecução do mais alto nível possível de saúde é a mais importante meta social mundial, cuja realização requer a ação de muitos outros setores sociais e econômicos, além do setor saúde. ${ }^{3}$

Em que pese o protocolo internacional e suas recomendações sobre o direito fundamental à saúde, o certo é que, em especial no Brasil, no Século XXI, a escassez de recursos, o desrespeito com a vida e dignidade humana, o desvio fraudulento do orçamento público continua a ser o símbolo do descaso das autoridades públicas para com o povo brasileiro.

O mais preocupante é o desequilíbrio entre as promessas da Constituição Federal de $1988^{4}$ e a deficiência das instituições encarregadas de prestar os serviços de saúde pública (Sistema Único de Saúde), realçando um importante defeito do sistema de direitos fundamentais: a extensão de direitos de cidadania à grande massa de homens e mulheres trabalhadores sem dar-lhes poder para agir sobre a realidade social em que vivem. (UNGER, 2015, p. 206)

A falta de médicos, a inexistência constante de remédio, de atendimento ambulatorial/hospitalar, a falta de equipamentos para a realização de exames de urgência e periódicos, a precariedade de leitos em Unidades de Terapia Intensiva - UTIs, faz com que o cidadão brasileiro, numa luta constante pela sobrevivência, bata às portas do Poder Judiciário, judicializando a questão da saúde, e, o que é mais estarrecedor, transferindo para o juiz brasileiro o poder de vida e morte em relação à pessoa humana.

3 Declaração de Alma-Ata - Conferência Internacional sobre cuidados primários da saúde: Disponível em: https://bvsms.saude.gov.br/bvs/publicacoes/declaracao_alma_ata.pdf. Acesso 05.03.2021.

$4 \quad$ A saúde é direito de todos, com garantia de acesso universal e igualitário, atendimento integral, gestão descentralizada e coordenada e participação social. O Brasil adotou os princípios clássicos de um Sistema Nacional de Saúde 
A legitimidade para realizar escolhas e sofrer as consequências políticas ou jurídicas não pode ser olvidada, especialmente quando essa escolha diz respeito a qual paciente deve ser atendido prioritariamente na hipótese da COVID, de um acidente com muitas vítimas, ou para quem deverá ser transplantado determinado rim, ou, ainda, se determinada pessoa poderá 'furar' a fila de internamento na UTI ou receber determinado medicamento em prejuízo de outras pessoas. (SCHULZE; NETO GEBRAN, 2015, p.25)

O juiz, diante desse lastimável quadro de descaso com a política pública da saúde, vê-se muitas vezes obrigado a transitar por critérios concernentes a prioridade, gestão ou alocação de recursos, racionamento em saúde.

O objetivo central deste trabalho, mediante uma metodologia crítica e de revisão estatística e bibliográfica, é justamente avaliar esse suposto "poder "divino" imposto ao magistrado brasileiro, bem como propor um critério indispensável para a construção de uma decisão justa e équo, tendo por fio condutor a formação humanística e interdisiciplinar do magistrado, que vá além de uma simples formação acadêmica da dogmática jurídica.

Conforme bem observaram Denise Almeida de Andrade e Roberta Laena Costa Jucá (2005, p. 8), todo processo de conhecimento é uma interpretação da realidade. É uma elevação, ao plano do pensar, da percepção imediata da realidade. Ele se insere no âmbito das duas possíveis atividades que o ser humano pode desenvolver, quando posto em contato com a realidade: reação, em que predomina o seu lado puramente instintivo e interpretação, quando transpõe para o plano do saber o seu contato preliminar com a realidade que o circunda.

Somente com a abertura e amplitude do conhecimento é que o magistrado poderá avaliar com maior sensibilidade/racionalidade e sensatez o grave problema da judicialização da saúde.

\section{A complexidade econômica e política do direito à saúde}

O Brasil tem destinado recursos à saúde menos do que a média mundial.

Dados da Organização mundial da Saúde (OMS) revelam que, em 2014, 6,8\% do orçamento público do governo federal eram destinados ao setor. No mundo, a média é de aproximadamente $11,7 \%$. Atualmente, a taxa é ainda menor à média do que se gasta na África, com $9.9 \%$ dos orçamentos nacionais para saúde. Nas Américas, a taxa é ainda de 
13,6\% contra 13.2\% na Europa. Nos Estados Unidos, 21,3\% do orçamento nacional vai para a saúde, contra 22\% na Suíça, 23\% na Nova Zelândia e 20\% no Japão. Em diversos países em desenvolvimento, o índice é maior que o do Brasil, como, por exemplo, no Uruguai, 20\%, Costa Rica, $23 \%$, e Nicarágua, $24 \% .^{5}$

Em uma comparação ao Produto Interno Bruto (PIB), a taxa no Brasil também é inferior à média internacional. No restante do mundo, cerca de 9,9\% do PIB se refere a gastos na Saúde. No Brasil, a taxa está em $8,3 \%{ }^{6}$

Na realidade, deve-se indagar se os cidadãos estão recebendo os serviços públicos de saúde que necessitam ter sem passar por dificuldades financeiras.

Para se ter uma ideia, conforme aduz Fabíola Supino Vieira (2016, p. 12), pesquisadora do Instituto de Pesquisa Econômica Aplicada (Ipea), entre 2002 e 2014, a alocação de recursos em ASPS pelas três esferas de governo aumentou de 94,6 para 216,6 bilhões de reais, em valores constantes de 2014, o que representa um aumento de $129 \%$. Porém, a participação da União no financiamento do Sistema Único de Saúde passou de 52\% para $42 \%$ no mesmo período, como mostra o gráfico indicado abaixo:

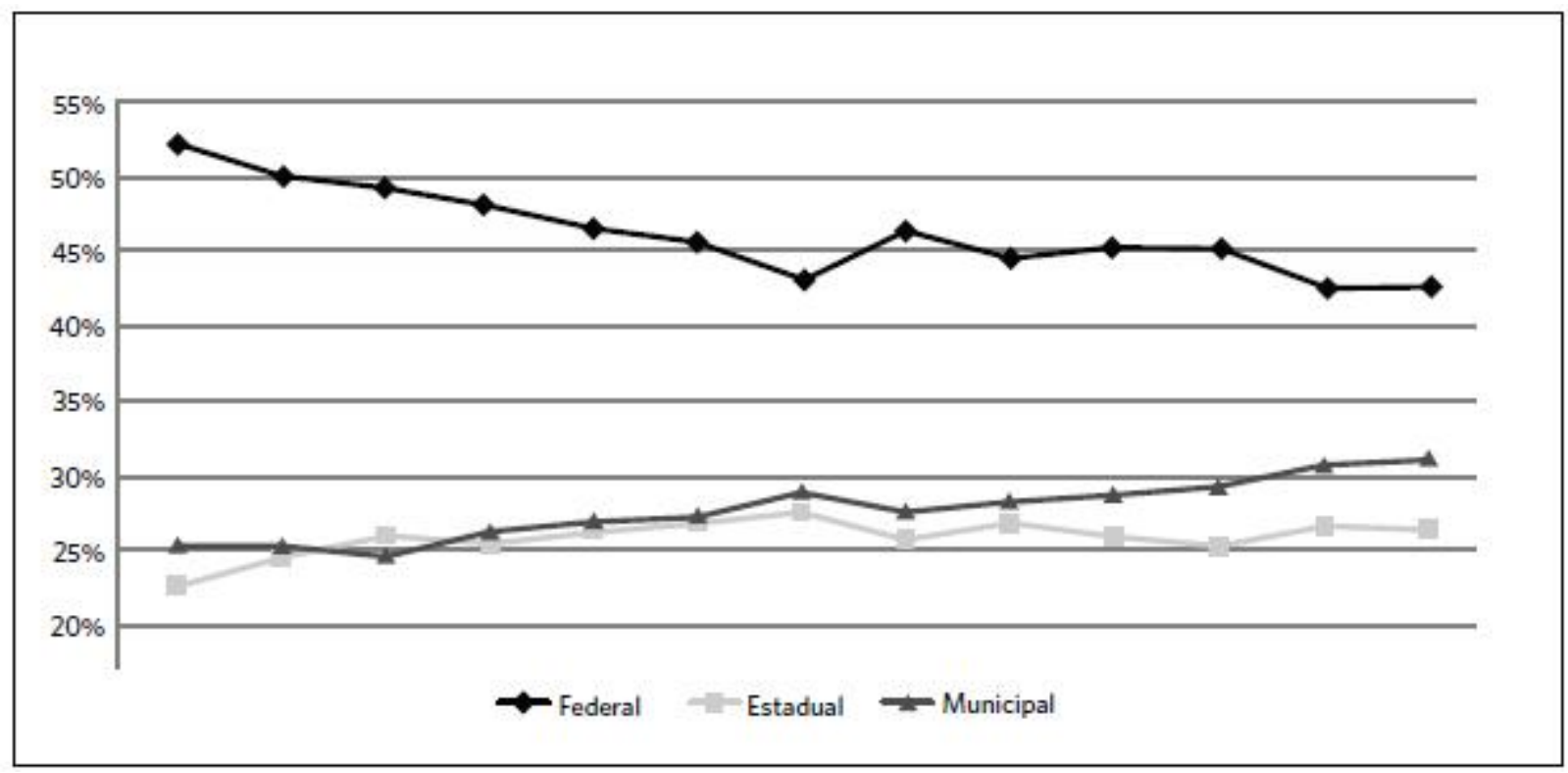

Juntamente com a questão da redução de recursos para financiamento da saúde, encontra-se a injustiça no tratamento não igualitário entre os cidadãos brasileiros. Segundo Ramiro Nóbrega Sant'ana (2017, p. 29), Unger considera que a saúde brasileira está inserida

5 Disponível em https://saude.estadao.com.br/noticias/geral,orcamento-para-saude-no-brasil-fica-abaixoda-media-mundial,70001788024. Acesso em 26.09.2018.

6 Disponível em https://saude.estadao.com.br/noticias/geral,orcamento-para-saude-no-brasil-fica-abaixoda-media-mundial,70001788024. Acesso em 26.09.2018. 
num sistema de apartheid: o dos planos privados e o do SUS, ambos financiados por recursos públicos. O primeiro possui financiamento per capita até três vezes maior que o segundo. $A$ "injustiça encarnada na relação entre esses dois mundos da saúde se traduz em desigualdades de vida e morte, de alívio e sofrimento".

Diante desse quadro orçamentário cada vez mais escasso para a saúde brasileira, em especial para o Sistema Único de Saúde - SUS, tem-se observado uma progressão geométrica na judicialização de questões concernentes ao direito à saúde.

Segundo o Ministério da Saúde, é crescente o impacto das determinações judiciais no orçamento da pasta. Em sete anos, o governo federal desembolsou R $\$ 4,5$ bilhões para atender as determinações judiciais para a compra de medicamentos, equipamentos, dietas, suplementos alimentares, gastos com cirurgias, internações e depósitos judiciais, um aumento de $1.010 \%$ entre 2010 e 2016. Em 2016, a cifra chegou a R \$ 1,3 bilhão, sendo que a compra dos dez medicamentos mais caros para atender as demandas judiciais custou ao Ministério da Saúde quase R\$1,1 bilhão, o que representou 90\% dos gastos totais dos 790 itens comprados em 2016. Segundo estudo do Tribunal de Contas da União (TCU), os gastos da União com processos judiciais referentes à saúde, em 2015, foram de $\mathrm{R} \$ 1$ bilhão, um aumento de mais de $1.300 \%$ em sete anos. O fornecimento de medicamentos, alguns sem registro no Sistema Único de Saúde, corresponde a $80 \%$ das ações. ${ }^{7}$

O grande volume de ações e o significativo impacto na gestão da saúde têm conduzido à intensificação das críticas no âmbito da pesquisa acadêmica, da mídia, da Administração Pública e do Legislativo. A partir de tais críticas, articulam-se inúmeras proposições para lidar com a supostamente excessiva intervenção judicial ou o efeito desestruturante da judicialização sobre o sistema de saúde. As propostas variam desde ponderações sobre um conjunto de medidas para realizar a "desjudicialização da saúde" até iniciativas legislativas para, literalmente, proibir decisões judiciais em determinadas situações. As diversas críticas e as iniciativas para, de variadas formas, se conter a judicialização merecem olhar cuidadoso e preocupado. Isso porque, a busca do sistema de justiça por garantir efetivo acesso à saúde tem sido alternativa utilizada por muitos indivíduos, em face da iniquidade e da exclusão decorrentes da desnaturação do modelo público de saúde brasileiro. Tolher esse instrumento de afirmação da cidadania sob uma suposta alegação de

\footnotetext{
$7 \quad$ Disponível em http://agenciabrasil.ebc.com.br/geral/noticia/2017-09/pacientes-cronicos-relatamdificuldades-no-acesso-medicamentos. Acesso em 27/09/2018.
} 
que a judicialização compromete a organização do sistema de saúde é ignorar as verdadeiras causas da desestrutução da saúde pública: a injustiça, a exclusão no acesso, o desfinanciamento do SUS, a segmentação do cuidado, a precarização dos serviços públicos (SANT'ANA, 2017, p. 263). ${ }^{8}$

Em face desse quadro sistêmico e endêmico da saúde pública brasileira, o Poder Judiciário, ao analisar determinada demanda sobre o direito à saúde, passa a ter o poder de vida ou morte, seja em relação àquele que ingressou com a ação, seja em relação àqueles (terceiros) que foram preteridos em face do atendimento preferencial dado pela decisão judicial.

É indubitável que a concessão de medicamento, a preferência de atendimento em determinada fila de atendimento urgente (cirurgia, transplante etc), ensejará prejuízos por vezes irreparáveis àqueles (terceiros/ sem o devido contraditório) que de alguma forma, direta ou indiretamente, serão atingidos pela decisão judicial.

Por isso, a complexidade de uma decisão que deverá ser proferida em demandas que tenham por objeto o 'direito à saúde', exige do magistrado uma formação interdisciplinar que vá além da formação da ciência dogmática jurídica.

Os 'fenômenos-inter' caracterizam-se por exigir, para seu diagnóstico, complexas estratégias de integração e diálogo que vão além da tolerante ‘justaposição’ (análise multi ou poli) e inclusive do cruzamento mais ou menos pontual das fronteiras (análise trans). (SOLSONA, 2012, p. 43)

Pode-se estabelecer uma distinção entre interdisciplinaridade, tomada em seu sentido restrito, e transdisciplinaridade. A primeira define-se por um encontro e colaboração entre duas ou mais disciplinas, mas cada uma delas sobre seus próprios esquemas conceituais e sobre o seu próprio método de investigação. A transdisciplinaridade, por sua vez, implica que o contato e a cooperação entre as disciplinas se dá por meio do mesmo paradigma, de certa maneira uma teoria social global ou "uma visão do mundo". (GUSDORF, 1977, p. 29)

\section{A compartimentação dos saberes como facilitação a uma visão simplista do direito à saúde}

\footnotetext{
8 Disponível em http://repositorio.uniceub.br/bitstream/235/12414/1/61350132.pdf. Acesso em
} 04.01.2019. 
Em decorrência do alto grau de complexidade e de periculosidade proveniente de uma decisão judicial que diga respeito à questão de política pública de saúde, a formação humanística e intelectual do juiz representa requisito importante para a prestação do exercício da tutela jurisdicional justa a équo.

O juiz, ao analisar políticas públicas sobre a saúde, deve ir além da dogmática jurídica, necessitando transitar por outros ramos do conhecimento, como, por exemplo, áreas da economia, filosofia, sociologia, orçamento público, gestão de saúde etc.

Porém, a própria formação acadêmica do magistrado nas Universidades por vezes contribui para que ele permaneça isolado em sua ciência jurídica, refratário ou temeroso à abertura para outros conhecimentos das ciências humanas afins.

A visão heurística do magistrado, como processo cognitivo empregado em decisões por vezes irracionais, é, sem dúvida, uma estratégia que ignora parte de informações importantes de outras disciplinas, com o objetivo principal de tornar célere, rápida e fácil a decisão judicial. O juiz, nessa perspectiva heurística, conforma-se com um conhecimento mínimo (fast and frugal heuristics) para fazer escolhas adaptativas em ambientes reais.

Modernamente, em que pese muito se diga sobre a necessidade de uma relação interdisciplinar entre os conhecimentos e disciplinas afins para o fim de se encontrar soluções profundas e consistentes para a resolução de problemas, concretamente muito pouco se tem feito para que isso ocorra efetivamente no mundo real e não permaneça circunscrito ao mundo das ideias.

Percebe-se que a compartimentação dos saberes que conduz a um isolamento entre as próprias disciplinas e ciências afins, cada qual perfazendo de seu método e de seus conceitos a única vertente possível para se chegar à verdade ou à Justiça, é reflexo das mudanças consideráveis do disciplinamento dos saberes que advém desde o Século XVIII, em decorrência daquilo que se costumou denominar de progresso da razão, o que, na verdade, não passava de um disciplinamento de saberes polimorfos e heterogêneos.

O aparecimento das Universidades, a partir do fim do Século XVIII e do início do século XIX, deveria ter contribuído para se evitar a compartimentação dos saberes. Friedrich August Wolf, Fichte e Schleiermacher redigem para a ocasião da fundação da Universidade de Berlim (1810), que será a universidade piloto do Século XIX europeu, alguns textos de notáveis interesses sobre a natureza e fundação da universidade: 
el teólogo, el filósofo y el filólogo señalan, cada uno por su parte, la necesidad de afirmar, en su lugar de elección, la solidaridad entre las disciplinas principales del conocimiento. La vida del espíritu es una vida en común; reúne, bajo la inspiración de una misma vocación, a hombres que persiguen investigaciones diferentes y se enriquecen mutuamente por el testimonio de la diversidad de sus intereses. En la universidad, cada orden de conocimientos existe por sí mismo, pero existe también por los demás, en su relación con la totalidad del saber. La institución universitaria define el emplazamiento interdisciplinario por excelencia; este carácter fue el de la universidad de Berlin durante la mayor parte del siglo XIX. (GUSDORF, 1983, p. 38)

Porém, conforme adverte Michel Foucault (2002, p. 219), o aparecimento das Universidades, na realidade, contribuiu muito para a consolidação da compartimentalização dos saberes, principalmente a partir da criação da universidade napoleônica, considerada como um grande aparelho uniforme dos saberes, com suas diferentes categorias e seus distintos prolongamentos.

Na perspectiva de Michel Foucault (2002, p. 219):

A universidade tem sobretudo uma função de seleção, não tanto das pessoas (afinal de contas, isso não é muito importante, essencialmente), mas dos saberes. O papel da seleção, ela o exerce com essa espécie de monopólio de fato, mas também de direito, que faz que um saber que não nasceu, que não se formou no interior dessa espécie de campo institucional, com limites aliás relativamente instável, mas que constitui em linhas gerais a universidade, os organismo oficiais de pesquisa, fora disso, o saber em estado selvagem, o saber nascido alhures, se vê automaticamente, logo de saída, se não totalmente excluído, pelo menos desclassificado a priori. Desaparecimento do cientista-amador: é um fato conhecido nos séculos XVIII - XIX. Portanto: papel de seleção da universidade, seleção dos saberes; papel de distribuição do escalonamento, da qualidade e da quantidade dos saberes em diferentes níveis; esse é o papel do ensino, com todas as barreiras que existem entre os diferentes escalões do aparelho universitário; papel de homogeneização desses saberes com estatuto reconhecido; organização de um consenso; e, enfim, centralização, mediação, mediante o caráter direto ou indireto, de aparelhos do Estado. Compreende-se o aparecimento, pois, de algo como a universidade, com seus prolongamentos e suas fronteiras incertas, no início do século XIX, a partir do momento em que, justamente, se operou esse pôr em disciplina os saberes, esse disciplinamento dos saberes.

O Século XVIII foi o século do disciplinamento dos saberes, ou seja, da organização interna de cada saber como uma disciplina, tendo, em seu campo próprio, a um só tempo critérios de seleção que permitem descartar o falso saber, o não-saber, formas de normalização e de homogeneização dos conteúdos, forma de hierarquização e, enfim, uma organização interna de centralização desses saberes em torno de um tipo de axiomatização de fato. 
E essa compartimentação dos saberes não constitui obra do acaso. Ao contrário, tem por finalidade disseminar a relação de poder entre as diversas disciplinas, uma vez que o poder não é uma propriedade, não é uma potência, mas, sim, é apenas uma relação que só se pode, e só se deve, estudar de acordo com termos entre os quais atua essa relação.

Percebe-se que a compartimentação dos saberes acarreta um imenso e múltiplo combate, não, pois, entre conhecimento e ignorância, mas um imenso e múltiplo combate dos saberes uns contra os outros - dos saberes que se opõem entre si por sua morfologia própria, por seus detentores inimigos uns dos outros e por seus efeitos de poderes intrínsecos. (FOUCAULT, 2002, p. 214)

O discurso de Charles Dupuy, em 1911, ao falar do fracasso da reconstrução da unidade do saber, assim se manifesta:

Esa palabra 'universidad' no es más que una palavra [...], porque no encierra una organización cujyos elementos sean solidários, cuyas partes se sientan órganos de un mismo todo [...]. Cada cual tira por su lado; los hombres del Derecho, los de Letras, forman otros tantos grupos aparte; en cada una de esas facultades, las especialidades forman asimismo grupos, yo no diria celosos, pero sí bastante cerrados los unos hacia los otros. Es de concocimiento público [...] que en la Sorbona, por ejemplo, está el grupo de los historiadores, el de los filósofos, y que existe muy poco contacto, y aun menor penetración entre ellos [...]. Por el momento, todo se somete a la especialización. (GUSDORF, 1983, p. 39)

Tal advertência feita no início do Século XX permanece vivia atualmente, pois ainda hoje o conhecimento humano está inserido numa "patologia do saber", o que representa uma particularidade da crise que atravessa a civilização humana. (JAPIASSÚ, 1976, p. 35).

Ferran Luiz Tarragò (2011, p. 136 e 137), ao analisar a interdisciplinaridade curricular no ensino moderno, assim se manifestou:

Así pues, la disciplinariedad curricular se instituye como el eje organizativo de la educación, con independencia de la posibilidad, planteable al menos como hipótesis, que pudiera haber otros criterios más idóneos para la estructuración de los aprendizajes. Del hecho que la división disciplinar tal vez refleje la mejor opción que hasta ahora ha podido encontrarse para estructurar el conocimiento humano no tiene por qué deducirse que también supone la mejor forma de introducir (que de esto se trata) a dicho conocimiento. Como demuestra Howard Gardner, incluso entre los mejores estudiantes es rara la comprensión genuina del pensamiento disciplinar, lo que se ponde de manifiesto cuando se les pregunta desde fuera del contexto académico en que han obtenido este conocimiento o se les pide que lo apliquen a otros ámbitos. En líneas generales, tanto los tradicionalistas como los progresistas han subestimado las dificultades que comporta la comprensión disciplinar, y todavía hoy son pocos los enseñantes que se atreven a confrontar las serias implicaciones de este hecho. Los más se refugian en sus compartimentos estancos, propiciando visiones 
esquemáticas, descontextualizadas y aisladas de su área de conocimiento. Una vantaja no desdeñable que obtienen con ello es que, además de cumplir con las normas establecidas, se evitan numerosas complicaciones.

$\mathrm{Na}$ realidade, a atual arquitetura das universidades (das quais saem os juízes brasileiro) corresponde a um sistema de ensino que foi desenhado para a transmissão oral do conhecimento e o controle físico dos alunos. Determinada por sua estática concepção decimonónica, o entorno físico da sala de aula condiciona em grande medida os objetivos educacionais, os métodos didáticos, as interações e os recursos que se podem empregar. A aprendizagem está umbilicalmente unida a esta realidade. Seu mesmo desenho constitui um sério freio a qualquer expectativa de mudança, que dê centralidade ao aprendiz. Ao longo de sua vigência, o espaço fechado das salas de aula materializou um estado de 'proibição ou suspensão das comunicações. (TARRAGÓ, 2011, p. 139 e 140)

O fracasso da epistemologia representa o fracasso humano em seu conjunto.

Na expressão de Carbonell (2011, p. 2):

la tecnología y su socialización generan tensiones y divisiones en nuestras estrutucturas etológicas y culturales. No se há producido, pues, uma socialización efectiva del conocimiento, y ello impide que caminemos hacia la sociedad del pensamiento, tal como deberíamos haber.

É importante salientar que conhecer pode significar para o magistrado obter uma representação de um objeto, no caso, uma questão envolvendo o direito à saúde. $\mathrm{O}$ conhecimento seria o resultado de referido processo, a representação mental, e abarca desde a apreensão de uma entidade simples ou de um processo prático simples até uma compreensão dos mecanismos mais profundos de funcionamento da realidade. $\mathrm{O}$ conhecimento, portanto, pode ser imediato, trivial e derivado de uma simples observação, ou pode requerer um esforço considerável se o objeto a ser apreendido (no caso as filigranas do direito à saúde) não é evidente à primeira vista. Em qualquer caso, o conhecimento é um produto, o resultado de processar internamente a informação que se obtém dos sentidos, mesclá-la com conhecimentos prévios, e elaborar estruturas que permitem ao magistrado entender, interpretar e, em última medida, ser consciente de todo o que lhe cerca no processo. É dizer, o conhecimento reside em nosso cérebro e é fruto dos processos mentais humanos. $\mathrm{O}$ que provém do exterior é, simplesmente, informação. (BREY, 2011, p. 57 e 58)

Mas para que esse conhecimento tenha amplo espectro, é necessário que a formação do magistrado provenha de um conhecimento simplificado (e não simplista) das diversas 
áreas das ciências humanas afins, numa relação interdisciplinar, rompendo-se com a compartimentação estagnada do isolamento da dogmática jurídica.

\section{A formação interdisciplinar, intercultural e macrofilosófica como requisito} indispensável para uma solução justa e équo em questões sobre direito à saúde

Ao se enfrentar um problema tão complexo, um enfoque interdisciplinar, intercultural e macrofilosófico, torna-se extremamente imprescindível.

De fato, seria ingenuidade supor que a solução - ou seja - a atuação da justiça em um caso concreto de direito à saúde possa ser encontrada consultando, unicamente, o caudal instrumental oferecido pela ciência do direito. (AMARAL, 2016, p.14)

Diante daquilo que Gonçal Mayos Solsona (2012, p. 12) denomina de 'humanidade turboglobalizada', a situação atual é angustiante, exigindo-se o rompimento de uma dinâmica que tem sido hegemônica durante décadas, para a realização de um diálogo entre as distintas disciplinas hiperespecializadas. Essas disciplinas devem ser retiradas de seu devaneio metodológico para que enfrentem os problemas humanos de hoje, que são globais e que pouco ou nada se circunscrevem a especialidades acadêmicas ou, inclusive, a fronteiras estatais.

Por isso, a problematização da Justiça propugna por:

aportaciones interdisciplinares que atiendan desde lo jurídico - el núcleo del 'nomos' global que es imperioso construir - a lo 'macrofilosófico' - es decir, las apuestas reflexivas más críticas y holistas - . Eso reto hacia lo inter, trans, multi, poli o - tendenciamente - postdisciplinar está, modestamente y desde la conciencia de sua imperiosa necesidad y de sus enormes dificultades, en la base de 'interrelación filosófica-jurídica multinível: estudios desde la interconstitucionalidad, interculturalidad e interdisciplinariedad para un mundo global. (SOLSONA, 2012, p. 12)

Em face desse complexo cenário, Gonçal Mayos Solsona (2012, p. 9 a 15) propõe um enfoque interdisciplinar, intercultural e macrofilosófico.

Há necessidade, portanto, de uma inter-relação filosófica-jurídica multinível.

Denominamos fenômenos inter:

a los que caracterizan y dan lugar a um mundo cada vez más integrado, interdependiente e interrelacionado. Organizado a través de instituciones o nódulos, que necesitan funcionar en constante vinculación y comunicación, y que solo puede definirse detalladamente en función de esas vinculaciones. (SOLSONA, 2016, p. 41) 
Os 'fenômenos-inter' caracterizam-se por exigir, para seu diagnóstico, complexas estratégias de integração e diálogo que vão além da tolerante ‘justaposição' (análise multi ou poli) e inclusive do cruzamento mais ou menos pontual das fronteiras (análise trans) (SOLSONA, 2016, p. 43).

Pode-se estabelecer uma distinção entre interdisciplinaridade, tomada em seu sentido restrito, e transdisciplinaridade. A primeira, define-se por um encontro e colaboração entre duas ou mais disciplinas, mas cada uma delas sobre seus próprios esquemas conceituais e sobre o seu próprio método de investigação. A transdisciplinaridade, por sua vez, implica que o contato e a cooperação entre as disciplinas se dá por meio do mesmo paradigma, de certa maneira uma teoria social global ou "uma visão do mundo". (GUSDORF, 1977, p. 29)

$\mathrm{Na}$ realidade, toda disciplina é resultado de um processo paradigmatizador e de 'separação disciplinar'; ou seja, todas as ciências tiveram uma origem pré e interdisciplinar por exemplo, a filosofia é denominada de "madre de todas las ciências". Ademais, os estudos pós-coloniais e decoloniais demonstram que também entre as epistemologias e os enfoques culturais produzem-se relações de subordinação e exclusão que reproduzem as dominações em função do poder. (SOLSONA, 2016, p. 44)

Os 'fenômenos-inter" e não meramente multi, poli e trans, obrigam a fortes dialéticas, profundas combinações e aceleradas integrações. Cada vez mais há necessidade de estratégias interdisciplinares, baseadas no efetivo diálogo e intercâmbio, mediante um completo reconhecimento mútuo e crescente fusão. (SOLSONA, 2016, p. 45)

Por isso, como sinal de um projeto unificado em prol da realização da Justiça, em especial da justiça sobre questão de saúde, as disciplinas acadêmicas devem ir mais além das muitas louváveis propostas multi, poli e inclusive transdisciplinares (cross-disciplinarity). Cada vez mais é maior a necessidade de investigações e de sínteses que reúnam múltiplas disciplinas ou paradigmas, que cruzem em todas as direções as fronteiras acadêmicas e que finalmente - integrem interdisciplinarmente as problemáticas e as teorias. (SOLSONA, 2016, p. 46 e 47$)$

Haverá necessidade daquilo que Marcelo Neves (2009, p. 117), ao tratar do ‘transconstitucionalismo', denomina de ‘conversação' ou 'diálogo' entre a dogmática jurídica e as demais disciplinas afins, que pode se desenvolver em vários níveis. Essa 'conversão', contudo, não deve conduzir a uma ideia de cooperação permanente entre as disciplinas, já que 
são constantes os conflitos entre os diversos problemas jurídicos e sociais, econômicos e culturais.

Para Marcelo Neves (2009, p. 122), se cada lei (no nosso caso, cada disciplina) quiser tratar do problema isoladamente, a fragmentação continuaria sem estrutura, razão pela qual necessita-se de um 'diálogo' ou 'conversação' interdisciplinar.

Porém, numa perspectiva 'inter', o diálogo ou conversão, apesar de importantes, não é suficiente para se buscar um critério de Justiça. Há necessidade de uma baja intensidad hierárquica, permeável pela circularidade de disciplinas de um modelo de integração 'em rede'. A interdisciplinaridade implica na atuação em rede para a solução de problemas de Justiça sobre questão de saúde. ${ }^{9}$

A metáfora das redes traduz a ausência de hierarquia entre as disciplinas, diferentemente do modelo multinível. (COELHO; CORDEIRO, 2016, p. 89)

Dessa forma, o sistema jurídico é integrado não somente por elementos do próprio sistema, senão por diferentes e distintos elementos de outros sistemas, que funcionam simultaneamente, formando todos juntos um sistema integrado, com engrenagens que lhe permite a interconexão, comunicação e funcionamento conjunto.

A abertura e a complexidade interdisciplinar não podem ser interpretadas como uma mera somatória de disciplinas afins e isoladas ou de comportamentos estanques, paralelos e sem qualquer conexão; pelo contrário, todas elas vêm formar, a partir de sua autonomia, uma unidade sistêmica, interconectada e dirigida a alcançar fins e objetivos comuns, no caso, a realização de Justiça.

Busca-se, portanto, uma unidade na diversidade.

Para Luiz Solano Carrera, Juiz da Corte Suprema de Justiça da Costa Rica, o fundamental na formação e capacitação do magistrado é o desenvolvimento da capacidade de trabalho interdisciplinar, a consulta a especialistas e uma visão mais ampla das situações. (TEIXEIRA, 1999, p. 35)

As conclusões do "Primeiro Congresso Internacional dos Magistrados" realizado em Roma, em 1958, aprovou, entre outras resoluções, especialmente a seguinte quanto à preparação do juiz para o exercício da função jurisdicional: "la formation du magistrat doit

9 É muito usual encontrar-se nos textos acadêmicos uma posição bem definida sobre a interdisciplinaridade do direito e outras ciências afins. Contudo, no momento em que se deve efetivamente por em prática essa racionalidade teórica, observa-se uma forte tendência dos juristas em geral, não somente na área processual, de realçar a total independência da ciência do direito, rechaçando qualquer influência, por vezes muito positivas dos outros ramos da ciência humana. 
tendre: à intégrer lês notions extrajudiciaires nécessaires à l'exercice de ses fonctions (études d'économie, de sociologie, de psycologie et de criminologie etc...". (TEIXEIRA, 1999 , p. 80)

O Poder Judiciário é um sistema que desenvolve suas atividades em um "ambiente", onde mantém várias relações com outros sistemas e subsistemas. (ZAFFARONI, 1995, p. 32)

$\mathrm{Na}$ realidade, "se existe uma verdade na sociedade, é a de que a neutralidade é impossível". (ROCHA, 1985, p. 32)

A análise da questão da Justiça na ótica deste trabalho reclama pontos de encontro e cooperação das disciplinas que formam as ciências humanas, construindo-se uma teia entre a dogmática jurídica e as disciplinas afins, em especial, a filosofia, tudo isso em prol da construção de uma decisão justa e équo em questão de direito à saúde.

Atualmente é impossível isolar um determinado tipo de investigação, sem colocá-la em contatos interdisciplinar. Jean Piaget preconiza que "tanto la evolución interna de su campo, como el desarrollo de los otros saberes obligan a tener en cuenta múltiples tendencias centrífugas que plantean inevitablemente problemas de conexiones interdisciplinarias". (BENOIST, 1983, p. 165)

Por sua vez, ensina Micjhel Serres:

El intercambio como ley de universo teórico, la transferencia de conceptos y su complicación, la intersección y el recubrimento de los campos, la conferencia indefinida del sentido en la especulación no referencia, imitan, y desde ahora representan, expresan y reproducen, el tejido mismo en que están sumidos los objetos que son las proprias cosas, la red compleja de la interinformación (1972, p. 15). (BENOIST, 1983, p. 166)

Atualmente, a realidade social e econômica caracteriza-se por uma interação cada vez mais próxima entre os processos técnicos ligados à produção, aos processos econômicos, aos processos políticos e sociais, aos processos culturais e espirituais. As relações que se travam no seio social apresentam-se mais estreitas do que aquelas observadas no princípio do século XX, sendo que toda modificação brusca que se possa evidenciar em um determinado setor, fatalmente se propagará mais ou menos rapidamente no seio dos outros, em função do grau de integração em que todos esses campos chegaram, ou estão a ponto de chegar, produzindo nestes últimos modificações que por sua vez voltem atuar sobre o organismo social completo. (SMIRNOV, 1983 p. 55)

A formação cultural representa a exclusão da monocultura jurídica e tem o objetivo de propiciar ao estudioso do direito uma visão integral das questões sobre as quais o direito 
incide, sem desprezar seus aspectos psicológicos, sociais, econômicos e históricos. Somente a multividência humanística permitirá o trato adequado às aflições convertidas em processo judicial. (TEIXEIRA, 1999, p. 102)

Propugnar-se pelo intercambio da análise dos elementos da dogmática jurídica com as ciências humanas afins, mediante uma perspectiva interdisciplinar, nada mais significa do que prosseguir no que parece uma única mão da política globalizada em que se encontra o mundo. Contudo, ao contrário do que possa a primeira vista parecer, essa sustentação interdisciplinar não significa um apoio à globalização econômica institucionalizada internacionalmente, mas, acima de tudo, resgatar o caráter humano das relações sociais.

A influência das ciências afins no âmbito dos sujeitos da relação jurídica processual é da seguinte ordem: a) as ciências sociais demonstram a formação cultural e ideológica dos sujeitos processuais; b) as ciências econômicas e políticas, a interferência do neo-capitalismo ou da globalização na formação subjetiva dos sujeitos processuais, bem como nas desigualdades empíricas daqueles que participarão dessa relação; c) a história nos permite refutar a verdade absoluta de alguns princípios e valores presentes na dogmática jurídica, bastando observar o conhecimento teórico instrumental e prático da civilização em relação ao louco, conforme bem demonstrou em seus trabalhos Michel Foucault; d) a psicologia e a psicanálise com suas pertinentes observações quanto à influência da consciência.

$\mathrm{Na}$ realidade, existe um processo mais ou menos espontâneo de cooperação interdisciplinar desencadeado pelas necessidades intelectuais ou científicas.

A interdisciplinaridade, segundo Edgar Morin e M. Piattelli-Palmarini, provém do mesmo fenômeno que representa da humanidade. (APOSTEL; BENOIST; BOTTOMORE; DUFRENNE; MOMMSEN; MORIN, E; PIATTELLI-PALMARINI; SMIRNOV; UI, 1983, p. 13)

Na concepção de Smirnov (1983, p. 13), o marco geral para a investigação científica e a união das diferentes disciplinas entre si, decorre da integração cada vez mais desenvolvida pela vida social, principalmente a partir do momento em que se concebe uma real importância à planificação do desenvolvimento econômico e social.

Pensar a dogmática jurídica desvinculada dessas circunstâncias sociais, seria o mesmo que o autoritário pensamento de Kant e sua tentativa de sistematizar o conhecimento, em detrimento de seus aspectos político-ideológicos, a procura de uma razão pura, tentativa 
infrutífera, mas nem por isso deixada de ser tentada na história, que procura adstringir os antagonismos sociais a um imaginário ideal. (ROCHA, 1985, p. 24)

\section{Conclusão}

A judicialização do direito à saúde não é uma questão simplista e de fácil solução.

O juiz, ao proferir sua decisão em questão de direito à saúde, ao mesmo tempo em que pode salvar a vida da parte postulante, também poderá condenar à morte outras pessoas que não fazem parte da relação jurídica processual.

Diante dessa complexidade, a formação acadêmica com base na dogmática jurídica do magistrado já não se mostra suficiente para a resolução de questões envolvendo o direito à saúde.

A ciência jurídica, indispensável para a realização da atividade jurisdicional, não se mostra mais segura e eficaz para a resolução de problemas que de certa forma ultrapassam os limites da relação jurídica processual.

Em razão dessa insuficiência cognitiva, a preocupação com uma decisão équo $e$ justa exige algo mais que a simples formação dogmática jurídica do magistrado.

Para que o juiz, diante de questões que envolvam o direito à saúde, possa dar uma solução équo e justa, é necessário uma formação interdisciplinar, intercultural e macrofilosófica, com a qual o magistrado tenha uma visão 'holística' e não simplesmente 'heurística' da problemática envolvendo a saúde do povo brasileiro.

Somente através dessa rede interdisciplinar das ciências humanas afins, poderá o magistrado avaliar com maior segurança e realista convicção os problemas que afligem à população brasileira no que concerne à política pública da saúde.

\section{Bibliografia}

AMARAL, Arnaldo José Duarte. La realización de la justicia en un mundo turboglobalizado: necesidad de un enfoque interdisciplinar. In: Interrelación filosófico - jurídica multinível: estúdios desde la interconstitucionalidad, la interculturalidad y la interdisicplinaridad para 
un mundo global. Org: Saulo de Oliveria Pinto Coelho; Alexandre Walmott e Moacir Henrique Junior. Barcelona: Ed: Macrofilosofía Linkgua, 2016.

ANDRADE, Denise Almeida; JUCÁ, Roberta Laena Costa. A concretização como opção hermenêutica para a interpretação dos direitos fundamentais. Vol. 10. n.1. 2005. http://periodicos.unifor.br/rpen/article/view/759/1621. Acesso em 05.03.2021.

APOSTEL, L; BENOIST, J. M.; BOTTOMORE, T.B.; DUFRENNE, M..; MOMMSEN, W.J.; MORIN, E.; PIATTELlI-PALMARINI, M.; SMIRNOV, S.N.; UI, J. Interdisciplinariedad y ciencias humanas. Trad. Jesús Gabriel Pérez Matin. Madrid: Editoral Tecnos, 1983.

BENOIST. Jean-marie. La interdisciplinariedad en las ciencias sociales. In: Interdisciplinariedad y ciencias humanas. Trad. Jesús Gabriel Péreza Martín. Madrid: Editorial Tecnos, 1983.

BREY, Antoni. La sociedad de la ignorancia. Una reflexión sobre la relación del individuo con el conocimiento en el mundo hiperconectado. In: GONÇAL MAYOS Y ANTONI BREY (EDS.), JOAN CAMPÁS, DANIEL INNERARITY, FERRAN RUIZ, MARINA SUBIRATS. La sociedad de la ignorancia. Barcelona: Península, 2011.

CARBONELL, Eudald. Prólogo, In: GONÇAL MAYOS Y ANTONI BREI (EDS.), JOAN CAMPÁS, DANIEL INNERARITY, FERRAN RUIZ, MARINA SUBIRATS. La sociedad de la ignorância. Barcelona: Ediciones Península, 2011.

COELHO, Saulo de Oliveira Pinto; CORDEIRO, Laís Vaz. Constitucionalismo multinivel, transconstitucionalismo e interconstitucionalismo, una crítica de tres modelos posibles para la comprensión de los fenómenos de integración e intercambio constitucional en iberoamérica. In: Interrelación filosófico - jurídica multinível: estúdios desde la interconstitucionalidad, la interculturalidad y la interdisicplinaridad para un mundo global. Org: Saulo de Oliveria Pinto Coelho; Alexandre Walmott e Moacir Henrique Junior. Barcelona: Ed: Macrofilosofía Linkgua, 2016.

DECLARAÇÃO DE ALMA-ATA. Conferência Internacional sobre cuidados primários da saúde: Disponível em: https://bvsms.saude.gov.br/bvs/publicacoes/declaracao_alma_ata.pdf. Acesso 05.03.2021.

FOUCAULT, Michel. Em defesa da sociedade. São Paulo: Martins Fontes, 2002.

GUSDORF, Georges. Passe, présent, avenir de la recherche interdisiciplinar: revue internacionale de sciences sociales (Paris, Unesco), XXIX, n. 4 (1977). 
GUSDORF. Georges. Pasado, presente y futuro de la investigacion interdisicplinaria. In Interdisciplinariedad y ciencias humanas. Trad. Jesús Gabriel Péreza Martín. Madrid: Editorial Tecnos, 1983.

Disponível em http://agenciabrasil.ebc.com.br/geral/noticia/2017-09/pacientes-cronicosrelatam-dificuldades-no-acesso-medicamentos. Acesso em 27/09/2018.

Disponível em https://saude.estadao.com.br/noticias/geral,orcamento-para-saude-no-brasilfica-abaixo-da-media-mundial,70001788024. Acesso em 26.09.2018.

JAPIASSU, H. Interdisciplinaridade e patologia do saber. Rio de Janeiro: Imag, 1976

NEVES, Marcelo. Transconstitucionalismo. São Paulo: Martins Fontes, 2009.

ROCHA, Leonel Severo. A problemática jurídica: uma introdução transdisciplinar. Porto Alegre: Sergio Antonio Fabris Editor, 1985.

SANT'ANA, Ramiro Nóbrega. A judicialização como instrumento de acesso à saúde: propostas de enfrentamento da injustiça da saúde pública. Disponível em http://repositorio.uniceub.br/bitstream/235/12414/1/61350132.pdf acesso em 04.01.2019.

SCHULZE, Clenio Jair; NETO GEBRAN, João Pedro. Direito à saúde - análise à luz da judicialização. Porto Alegre: Verbo, 2015.

SMIRNOV, Stanislav Nikolaevitch. La aproximacion interdisciplinaria en la ciencia de hoy fundamentos ontologicos y epistemológicos - formas y funciones. In: Interdisciplinariedad y ciencias humanas. Trad. Jesús Gabriel Péreza Martín. Madrid: Editorial Tecnos, 1983.

SOLSONA, Gonçal Mayos, Nuevos 'fenómenos'-inter: interconstitucionalidad e interculturalidad'. In: Interrelación filosófico - jurídica multinível: estúdios desde la interconstitucionalidad, la interculturalidad y la interdisicplinaridad para un mundo global. Org: Saulo de Oliveria Pinto Coelho; Alexandre Walmott e Moacir Henrique Junior. Barcelona: Ed: Macrofilosofía Linkgua, 2016.

SOLSONA, Gonçal Mayos. Macrofilosofia de la globalización y del pensamiento único, un macroanálisis para el 'empoderamiento’. Barcelona: Editorial Académica Española, 2012.

TARRAGÒ, Ferran Ruiz. Educar, entre la evasión y la utopía. In: GONÇAL MAYOS Y ANTONI BREI (EDS.), JOAN CAMPÁS, DANIEL INNERARITY, FERRAN RUIZ, MARINA SUBIRATS. La sociedad de la ignorância. Barcelona: Ediciones Península, 2011. TEIXEIRA, Sálvio de Figueiredo. O juiz - seleção e formação do magistrado no mundo contemporâneo. Belo Horizonte: Del Rey, 1999. 
VIEIRA, Fabíola Sulpino . Implicações de decisões e discussões recentes para o financiamento do sistema único de saúde. In: Saúde Debate. vol.40. no.109. Rio de Janeiro. Apr./Jun. 2016.

http://www.scielo.br/scielo.php?script=sci_arttext\&pid=S0103-11042016000200187. Acesso em 27/09/2018.

ZAFFARONI, Eugenio Raul. Poder judiciário - crise, acertos e desacertos. Trad. Juarez Tavares. São Paulo: Editora Revista dos Tribunais, 1995. 